\title{
The Effect of Perioperative Uveitis Control on the Success of Glaucoma Surgery in Uveitic Glaucoma
}

This article was published in the following Dove Press journal:

Clinical Ophthalmology

\section{Moustafa S Magliyah (D) Abdulrahman $\mathrm{H}$ Badawi $^{2}$ \\ Abdulaziz A Alshamrani (iD ${ }^{2}$ \\ Rizwan Malik ${ }^{3}$ \\ Hassan Al-Dhibi \\ 'Ophthalmology Department, Prince Mohammed Medical City, AlJouf, Saudi Arabia; ${ }^{2}$ Vitreoretinal Division, King Khaled Eye Specialist Hospital, Riyadh, Saudi Arabia; ${ }^{3}$ Glaucoma Division, King Khaled Eye Specialist Hospital, Riyadh, Kingdom of Saudi Arabia}

\section{Video abstract}

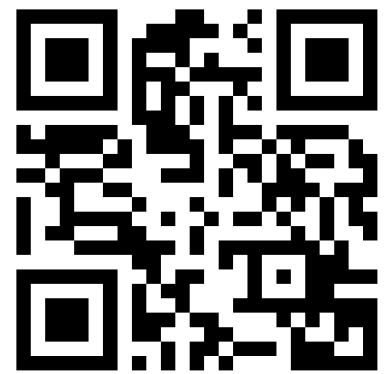

Point your SmartPhone at the code above. If you have a $Q R$ code reader the video abstract will appear. Or use: https://youtu.be/ipqFhnuxRIg
Correspondence: Moustafa S Magliyah Vitreoretinal Division, King Khaled Eye Specialist Hospital, Al- Oruba Street, PO Box 7I9I, Riyadh, I I462, Kingdom of Saudi Arabia

Tel +966 II 482 I 234 ext. 2655

Fax +966 II $482 I 234$ ext. 3773

Email mussam8@yahoo.com
Purpose: To study the effects of perioperative uveitis control (PUC) on postoperative intraocular pressure (IOP) and uveitis activity in uveitic glaucoma (UG) patients who required glaucoma surgeries.

Patients and Methods: A retrospective chart review of 109 patients (120 eyes) which had glaucoma surgery for UG. A total of 66 eyes which had PUC were compared to 54 eyes which did not have. Measurements of IOP and uveitis activity were recorded preoperatively and over 2 years postoperatively. Average number of antiglaucoma medications and frequency of surgical failure were obtained in both groups.

Results: Over 2 years postoperatively, average IOP was lower in eyes which had PUC. Significant differences in IOP were found at 3 months $(P=0.004), 6$ months $(P=0.001)$, 1 year $(\mathrm{P}<0.001)$, and 2 years $(\mathrm{P}<0.001)$. Lower grades of anterior chamber $(\mathrm{AC})$ inflammation were found in eyes which had PUC. Significant differences were found at 1 month $(\mathrm{P}<0.001), 3$ months $(\mathrm{P}<0.001)$ and 6 months $(\mathrm{P}=0.001)$. Mean number of antiglaucoma medications at last visit was $0.7 \pm 1.1$ for eyes which had PUC and $2.6 \pm 1.5$ for eyes which did not have PUC $(\mathrm{P}<0.001)$. Among eyes which had PUC, only two eyes required second glaucoma surgeries, while 16 eyes with no $\mathrm{PUC}$ required further glaucoma surgeries after $27.7 \pm 12.5$ months $(\mathrm{P}<0.001)$.

Conclusion: Proper PUC in patients going for UG surgeries results in lower IOP levels and less AC inflammation over 2 years postoperatively. A comprehensive PUC regimen is needed for uveitic glaucoma patients going for surgeries.

Keywords: perioperative uveitis control, uveitic glaucoma, glaucoma surgeries, immunosuppressive therapy

\section{Plain Language Summary}

Glaucoma surgeries have variable long-term success rates in uveitic glaucoma. Unlike elective intraocular surgeries which require 3 months of inactive eye inflammation prior, glaucoma surgeries are done on an urgent basis to avoid permanent visual loss. Our findings in this paper suggest that perioperative control of uveitis can improve surgical success rates in uveitic glaucoma surgeries.

\section{Introduction}

Uveitic glaucoma (UG) is defined as an elevation of intraocular pressure (IOP) in association with uveitis resulting in optic nerve damage and glaucomatous visual field loss. ${ }^{1}$ Features of uveitis which lead to glaucoma include posterior or peripheral anterior synechiae formation, trabecular outflow obstruction through accumulation of proteins, inflammatory cells, or debris, and the use of corticosteroids to control inflammation. ${ }^{2}$ 
Around $30 \%$ of UG patients require surgical intervention. ${ }^{3}$ Success rate of glaucoma surgery in uveitis patients is variable. The reported success rates for trabeculectomy in UG range from $50 \%$ to $100 \%{ }^{4-6}$ and glaucoma drainage devices (GDD) success rates range from 57 to $94 \% \%^{7-9}$ This variability in success rates in previous studies is caused by multiple factors. First, the use of anti-metabolites like 5-fluorouracil (5FU) and mitomycin $\mathrm{C}$ (MMC) which are reported to improve outcomes in $\mathrm{UG}^{4-6}$ The second factor is the duration of follow-up and the definition of early vs late success. Although glaucoma surgical failure can occur as early as six months and as late as 5 years, there is no standardized duration to make this differentiation.

An important factor which plays a key role in surgical outcome and causes variability in success rates is the level of control of intraocular inflammation. This was first noticed by Hill et al, who found that 5 out of 7 eyes with significant postoperative inflammation, the filtration surgery failed. Moorthy et al recommended tight control of uveitis in preparation for intraocular surgery. Their suggested perioperative regimen for elective surgeries included hourly topical prednisolone and oral prednisone $40 \mathrm{mg}$ daily one week prior to surgery and postoperatively, topical and systemic steroid tapering based on the severity of intraocular inflammation. ${ }^{10}$ In emergency cases, they suggested a high dose of $1-1.5 \mathrm{mg} / \mathrm{kg} /$ day and hourly topical corticosteroid drops to be given prior to and tapered after surgery. However, there are several factors which need to be considered before deciding how to control uveitis perioperatively. These factors include different anatomical locations affected, variety of the uveitic entities, and remission/ relapse history.

To the best of our knowledge, the effect of proper uveitis control on the success of glaucoma surgery for UG has not been reported in the literature. In this study, we investigate the results of perioperative uveitis control (PUC) in patients who required UG surgeries and compare them to patients without PUC.

\section{Methods}

\section{Study Design}

This was a retrospective chart review conducted for consecutive patients with UG who underwent glaucoma surgery at King Khaled Eye Specialist Hospital (KKESH) in Riyadh, Saudi Arabia between 2002 and 2019. The research was conducted in accordance with the Declaration of Helsinki for research involving humans, and Institutional Review Board approval was obtained from KKESH.

\section{Patient Identification}

The term (uveitic glaucoma) was used to search the electronic medical records of the patients at KKESH. Patients were further categorized according to their medical or surgical managements. Eyes with glaucoma prior to the onset of uveitis, non-glaucomatous optic neuropathy, prior intraocular surgery, incomplete follow-up, or which developed early postoperative surgery-related complications which affected uveitis activity and IOP assessment were excluded.

\section{Data Collection}

For eligible patients, deidentified medical records were reviewed. Data collected from patients' medical records included age, gender, eye side, anatomical location (anterior, intermediate, posterior or panuveitis), uveitis diagnosis, duration of uveitis, duration of glaucoma, total duration of follow-ups. In the last preoperative visit, number of antiglaucoma drops, frequency of topical steroids, number and type of systemic uveitis treatments were obtained.

Detailed ophthalmic examination data in the last preoperative and each postoperative visit (1 month, 3 months, 6 months, 1 year and 2 years, respectively) included Snellen visual acuity (VA; converted to logarithm of minimal angle of resolution [logMAR] for statistical analysis), IOP measured by Goldman applanation tonometry, measurement of anterior chamber (AC) cellular activity according to the Standardization of Uveitis Nomenclature (SUN) Working Group criteria, ${ }^{11}$ number of IOP-lowering medications, number of immunomodulatory medications, visual acuity, and presence of postoperative complications.

\section{Glaucoma Procedures and Surgical Technique}

Eyes underwent either deep sclerectomy (DS) with adjuvant MMC, trabeculectomy with adjuvant MMC, or a GDD. The type of procedure was chosen based on what the surgeon thought would provide the best long-term outcome. Details of DS, GDD and cyclophotocoagulation performed at KKESH have been described previously. ${ }^{12,13}$

\section{Perioperative Uveitis Management}

All data regarding PUC were obtained. There are 3 management regimens to control uveitis in preparation for glaucoma surgery. The choice of regimen used for each patient was 


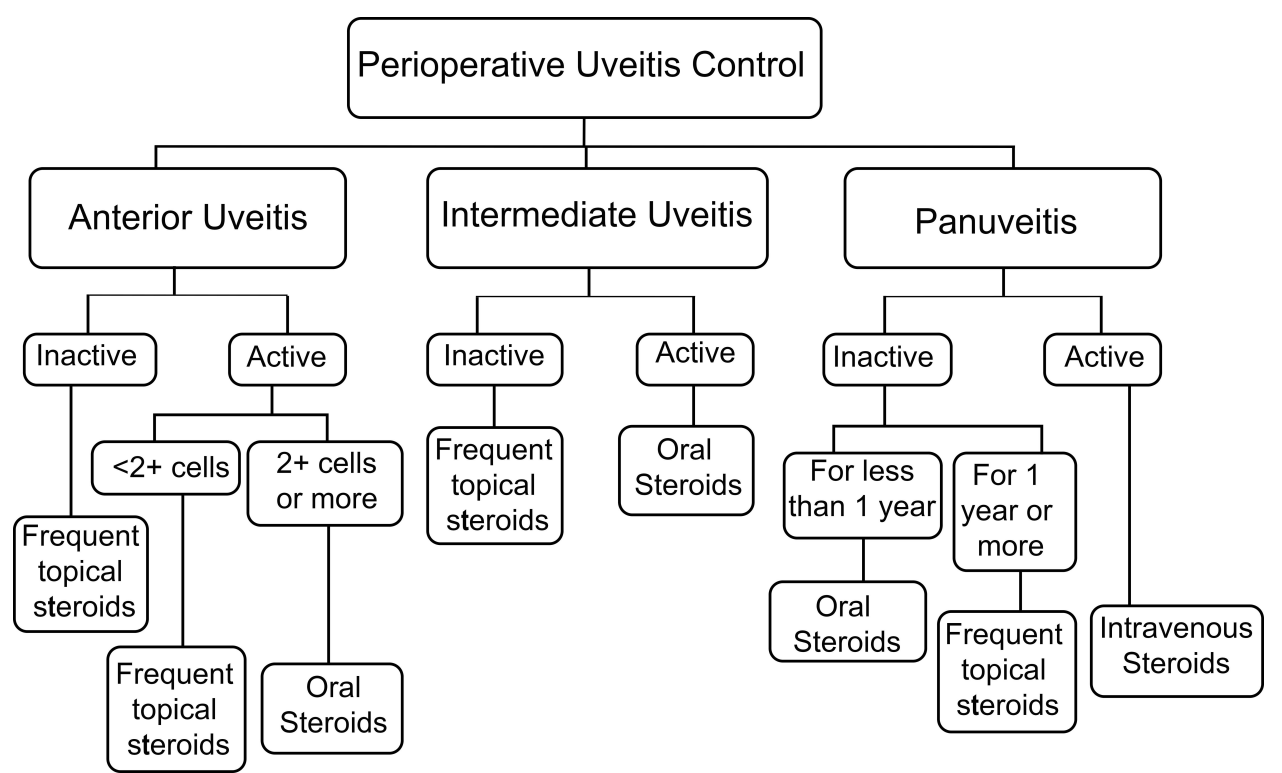

Figure I Flowchart of the perioperative uveitis control which was used for uveitic glaucoma patients who required glaucoma surgeries. Frequent topical steroids: hourly topical steroids I week preoperatively with postoperative tapering. Oral steroids: I $\mathrm{mg} / \mathrm{kg} /$ day oral steroids with hourly topical steroids I week preoperatively with postoperative tapering. Intravenous steroids: I gram intravenous steroids 3 days preoperatively with postoperative oral steroids tapering. Patients should continue using other systemic immunosuppressive medications.

based on the anatomical location and the status of uveitis activity in the last preoperative visit (Figure 1). The first regimen is the hourly topical prednisolone acetate $1 \% 3-5$ days preoperatively and 1 week postoperatively on weekly tapering dosage. This regimen was used in anterior uveitis cases which were inactive or had less than $2+$ cells, inactive intermediate uveitis, as well as inactive panuveitis cases for more than 1 year. The second regimen is the 1 milligram (mg)/kilogram $(\mathrm{kg}) /$ day oral prednisolone given 1 week preoperatively and continued for 1 week postoperatively followed by tapering dosage. This regimen was used in anterior uveitis cases which had $2+$ or more activity, active intermediate uveitis and panuveitis cases which were inactive for less than 1 year. The third regimen is the use of 1 gram intravenous methylprednisolone for 3 days preoperatively followed by $1 \mathrm{mg} / \mathrm{kg} /$ day oral prednisolone tapered weekly. This regimen was used in active panuveitis cases going for glaucoma surgeries.

\section{Outcome Measures}

The primary outcome measure in this study was the longterm IOP reduction. A secondary outcome measure was the surgical failure, defined as an IOP which was not controlled by full topical antiglaucoma agents and necessitating another glaucoma surgery. In eyes which required topical antiglaucoma agents postoperatively, the variability of time of initiation of antiglaucoma and the number of agents used have limited the ability to perform statistical analysis.

\section{Statistical Analysis}

Statistical analysis was performed using Statistical Package for Social Sciences (SPSS) v.22 (SPSS, Chicago, IL, USA). Clinical characteristics of the study population were analyzed using descriptive statistics. Univariate comparisons between treatment groups were conducted using analysis of variance (ANOVA) test for continuous variables and the $\chi^{2}$ test for categorical variables. The time to failure analysis was performed using Kaplan-Meier curves. A P value of less than 0.05 was considered statistically significant.

\section{Results}

A total of 683 patients with a diagnosis of UG were found. Among these, 149 eyes of 138 patients (20.2\%) required surgical interventions. Among the 149 eyes which had UG surgeries, 29 eyes were excluded. Causes of exclusion were exposure to previous intraocular surgeries which might have masqueraded the effect of uveitis on IOP in 21 patients, early surgery-related complications which have interfered with postoperative uveitis evaluation in 6 eyes (microbial keratitis (1), endophthalmitis (1), malignant glaucoma (1) and bullous keratopathy requiring corneal graft surgery (1) and early tube exposure requiring surgical removal (2)) and a further 2 eyes of 2 patients were lost to follow-up and therefore excluded from the 
study. The final sample consisted of 120 eyes of 109 patients.

Among patients included in our study, 45 patients (41.3\%) were males. 11 patients (6 males and 5 females) had bilateral UG surgeries. Mean age at diagnosis of UG was $37.3 \pm 17.7$ years. $42.9 \%$ of patients had anterior uveitis, $37.5 \%$ had panuveitis and $13.3 \%$ had intermediate uveitis. The most common uveitic entities were idiopathic anterior non-granulomatous uveitis (25.8\%) followed by Vogt Koyanagi Harada disease (VKH) (24.2\%) and presumed intraocular tuberculosis $(10.6 \%)$. Mean duration of uveitis was $81.4 \pm 59.2$ months (about 6.5 years) and mean duration of glaucoma was $56.1 \pm 45.7$ months (around 4.5 years). Mean number of glaucoma topical medications in the last preoperative visit was 3.7 agents. $55 \%$ of patients were on systemic medications to control uveitis. Mean number of systemic uveitis agents preoperatively was 1.8 \pm 0.7 agents. These agents included oral steroids $(75.8 \%)$, mycophenolate mofetil (43.9\%), methotrexate (18.2\%), adalimumab (16.7\%), cyclosporin (13.6\%), azathioprine $(10.6 \%)$ and infliximab (6.1\%). $23.7 \%$ of patients with anterior uveitis were on systemic medications, while $75 \%$ and $88.9 \%$ of intermediate and posterior uveitis were on systemic medications. Mean preoperative visual acuity was $1.1 \pm 0.8($ Snellen $=20 / 250)$ and mean IOP was $33.5 \pm 7.7$ $\mathrm{mmHg}$. Mean total duration of follow-ups for included patients was $91.3 \pm 52.8$ months (about 7.5 years). Preoperatively inactive inflammation was found in $42.5 \%$ of eyes with anterior uveitis, $31.3 \%$ of intermediate uveitis eyes and $13.3 \%$ of eyes with panuveitis. Preoperative topical steroids were used twice daily in $39.2 \%$, once daily in $28.3 \%$. $40 \%$ of patients had GDD, $30 \%$ had trabeculectomy with MMC, 23.3\% had DS with MMC and 6.7\% had CPC. Mean IOP postoperatively at 1 month was $12.9 \pm 8.1$ $\mathrm{mmHg}, 14.4 \pm 6.6 \mathrm{mmHg}$ at 3 months, $15.4 \pm 6.8 \mathrm{mmHg}$ at 6 months, $16.1 \pm 7.4 \mathrm{mmHg}$ after 1 year and $16.0 \pm 6$ mmHg after 2 years (Supplementary Figure S1). $43.3 \%$ of eyes were quiet after 1 month postoperatively, $66.7 \%$ after 3 months, 82.4\% after 6 months, 95.8\% after 1 year, and $100 \%$ after 2 years. Mean number of drops after 2 years postoperatively was 1.3 drops. Mean final BCVA was $0.97 \pm$ $0.99($ Snellen $=20 / 200)$.

PUC was performed pre-operatively in 66 eyes $(55 \%)$, while 54 eyes $(45 \%)$ had glaucoma surgeries without PUC. Demographics of patients and preoperative data in both groups are summarized in Table 1. PUC was with oral steroids in $28.3 \%$, topical steroids $26.5 \%$ and intravenous steroids in $23.5 \%$. Postoperatively, $73.5 \%$ had oral steroids
Table I Demographics of Patients and Preoperative Data of Eyes Which Had Perioperative Uveitis Control (PUC) and Eyes without PUC

\begin{tabular}{|c|c|c|}
\hline $\begin{array}{l}\text { General and Preoperative } \\
\text { Characteristics }\end{array}$ & $\begin{array}{l}\text { Eyes with } \\
\text { PUC (66 } \\
\text { Eyes) }\end{array}$ & $\begin{array}{l}\text { Eyes without } \\
\text { PUC (54 } \\
\text { Eyes) }\end{array}$ \\
\hline Age (years) & $33.9 \pm 16.8$ & $41.5 \pm 18.1$ \\
\hline Gender (M:F) & 23: 34 & $21: 31$ \\
\hline $\begin{array}{l}\text { Anatomical location (\%) } \\
\text { Anterior uveitis } \\
\text { Intermediate uveitis } \\
\text { Panuveitis }\end{array}$ & $\begin{array}{l}36.4 \\
12.1 \\
51.5\end{array}$ & $\begin{array}{l}64.8 \\
14.8 \\
20.4\end{array}$ \\
\hline Uveitis diagnosis (\%) & $\begin{array}{l}\text { VKH (34.8) } \\
\text { Idiopathic } \\
\text { anterior non- } \\
\text { granulomatous } \\
\text { uveitis (2I.2) } \\
\text { Presumed } \\
\text { intraocular } \\
\text { tuberculosis } \\
(9.1)\end{array}$ & $\begin{array}{l}\text { Idiopathic } \\
\text { anterior non- } \\
\text { granulomatous } \\
\text { uveitis (3I.5) } \\
\text { Herpetic } \\
\text { kerato-uveitis } \\
\text { (16.7) } \\
\text { Presumed } \\
\text { intraocular } \\
\text { tuberculosis } \\
\text { (I3) }\end{array}$ \\
\hline $\begin{array}{l}\text { Duration of glaucoma } \\
\text { (months) }\end{array}$ & $48.5 \pm 40.5$ & $65.3 \pm 50.2$ \\
\hline Duration of uveitis (months) & $72.6 \pm 50.5$ & $92.2 \pm 67.2$ \\
\hline $\begin{array}{l}\text { Total duration of follow-ups } \\
\text { (months) }\end{array}$ & $84.4 \pm 43.9$ & $99.7 \pm 61.9$ \\
\hline Preoperative IOP $(\mathrm{mmHg})$ & $34.7 \pm 7.3$ & $32.0 \pm 8.0$ \\
\hline $\begin{array}{l}\text { Preoperative inflammation } \\
\text { (Active \%) }\end{array}$ & 25.8 & 35.2 \\
\hline $\begin{array}{l}\text { Systemic uveitis medications } \\
(\text { Yes\%) }\end{array}$ & 69.7 & 37.0 \\
\hline $\begin{array}{l}\text { Number of systemic uveitis } \\
\text { medications }\end{array}$ & $1.4 \pm 1.1$ & $0.57 \pm 0.84$ \\
\hline Type of glaucoma surgery (\%) & & \\
\hline GDD & 36.4 & 44.4 \\
\hline Trabeculectomy with MMC & 34.8 & 24.1 \\
\hline DS with MMC & 25.8 & 20.4 \\
\hline CPC & 3 & II.I \\
\hline
\end{tabular}

Abbreviations: CPC, cyclophotocoagulation; DS, deep sclerectomy; F, females; GDD, glaucoma drainage device; IOP, intraocular pressure; M, males; MMC, mitomycin C; PUC, perioperative uveitis control; VKH, Vogt Koyanagi Harada.

and $26.5 \%$ had frequent topical steroids. Throughout the 2-year postoperative follow-up period, the group without PUC had higher mean IOP than the group with PUC (Figure 2). The difference in IOP was not significant after 1 


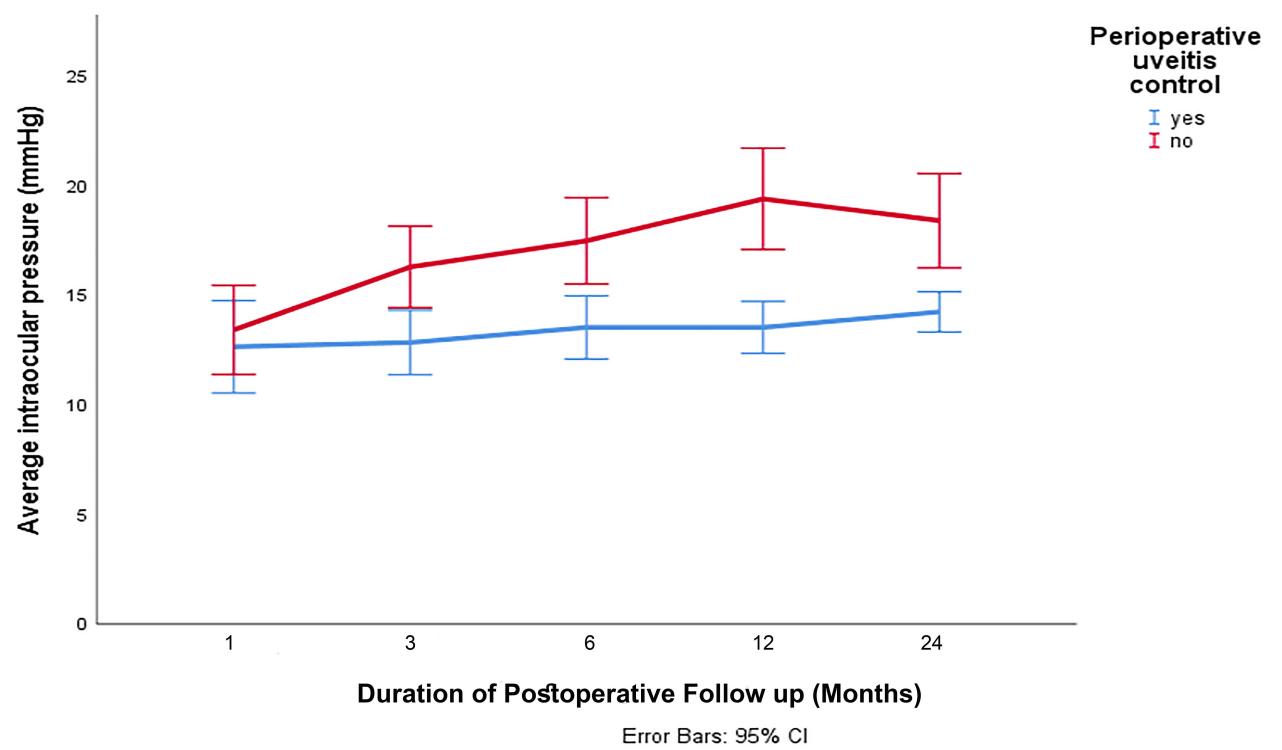

Figure 2 Difference in mean intraocular pressure (IOP) between eyes which had perioperative uveitis control (blue line) and eyes which did not have perioperative uveitis control (red line) over 2 years.

month $(\mathrm{P}=0.604)$ but was significantly higher afterwards $(\mathrm{P}$ $=0.004$ and 0.001 after 3 and 6 months respectively and $\mathrm{P}<$ 0.001 afterwards). A significantly higher number of eyes were found to be quiet in the early postoperative period (1 month, 3 months and 6 months, respectively) compared with eyes without PUC which were slower to achieve uveitis inactivity (Table 2).
Among 18 eyes which required second glaucoma surgeries, only two eyes had PUC after 13 and 15 months, while 16 eyes $(29.6 \%)$ among eyes which had no PUC required other surgeries after $27.7 \pm 12.5$ months $(\mathrm{P}<$ 0.001). There was a significant difference in the number of glaucoma drops 2 years postoperatively between patients with and without PUC $(\mathrm{P}<0.001)$. Mean final

Table 2 2-Year Follow-Up Results and Need for Second Surgery in Eyes with and without Perioperative Uveitis Control

\begin{tabular}{|l|c|c|c|}
\hline Postoperative Findings & Patients with PUC (66 Eyes) & Patients without PUC (54 Eyes) & P value \\
\hline I month IOP (mean \pm SD) & $12.64 \pm 8.6$ & $13.4 \pm 7.4$ & 14.8 quite \\
AC Activity (\%) & 66.7 quite & 74.1 trace \\
\hline 3 months IOP (mean \pm SD) & 33.3 trace & $16.3 \pm 6.8$ \\
& $12.8 \pm 5.9$ & 50 quite & 0.001 \\
AC Activity (\%) & 80.3 quite & 50 trace \\
\hline 6 months IOP (mean \pm SD) & 19.7 trace & $17.6 \pm 7.2$ \\
\hline AC Activity (\%) & $13.5 \pm 5.9$ & 68.5 quite \\
\hline I year IOP (mean \pm SD) & 93.8 quite & 29.6 trace \\
\hline AC Activity (\%) & $6.2 \%$ trace & $19.3 \pm 8.6$ & 0.001 \\
\hline 2 year IOP (mean \pm SD) & $13.5 \pm 4.9$ & 92.5 quite \\
\hline AC Activity (\%) & 95.4 quite & 7.5 trace \\
\hline Number of antiglaucoma drops postoperatively (mean \pm SD) & $5.6 \%$ trace & $19.3 \pm 8.6$ \\
\hline Need for another glaucoma surgery (\%) & $14.2 \pm 3.7$ & 96.2 quite \\
\hline
\end{tabular}

Abbreviations: AC, anterior chamber; IOP, intraocular pressure; SD, standard deviation; PUC, perioperative uveitis control. 
BCVA for patients who had PUC was $0.72 \pm 0.86$ (Snellen $=20 / 100$ ) and patients without PUC was $1.3 \pm 1.1$ (Snellen $=20 / 400)$. Patients with PUC had a significantly lower number of antiglaucoma drops postoperatively than patients without PUC $(\mathrm{P}<0.001)$. There was no significant difference in the number of postoperative antiglaucoma drops between eyes which had active uveitis and eyes which did not have active uveitis postoperatively $(\mathrm{P}=0.357)$.

Among 120 eyes included in our study, 18 eyes (15\%) required second glaucoma surgery. The first glaucoma surgery was DS with MMC in 2 patients, trabeculectomy with MMC in 7 patients, tube surgery in 7 patients and CPC in 2 patients. The failure rate was $7.1 \%$ in DS with MMC, $19.4 \%$ in trabeculectomy with MMC, $14.6 \%$ in tube surgery and $25 \%$ in CPC. Mean duration between both glaucoma surgeries was $26.8 \pm 13$ months. The cumulative probability of reoperation for IOP control (Figure 3) was greater ( $\mathrm{P}<0.001)$ in eyes without PUC (16 eyes) compared with eyes which had PUC ( 2 eyes). In order to explore the risk factors for further glaucoma surgery, a comparison of the age of the patients, the gender, the duration of glaucoma, the duration of uveitis, the anatomical location, the uveitis diagnosis, the number of systemic uveitis medications, the preoperative IOP, the preoperative level of uveitis activity, and the type of glaucoma surgery was performed (Table 3 ). Significant differences in the duration of glaucoma $(\mathrm{P}=0.013)$, the duration of uveitis ( $\mathrm{P}=0.008)$, and the use of systemic medications
(0.045) were found. A borderline significant lower number of systemic medications was found in patients who needed another glaucoma surgery.

\section{Discussion}

In the present study, we evaluated the effect of PUC on IOP and uveitis activity in patients undergoing glaucoma surgery. For uveitis patients going for cataract surgery, the inflammation is recommended to be quiet for at least 3 months prior. ${ }^{14,15}$ Unlike elective surgeries, glaucoma and vitreoretinal surgeries in uveitis patients is usually done on an emergency basis, making this rule a difficult one to adhere to. Previous studies have reported successful outcomes in vitrectomy without complying to the 3-month-inactivity rule. $^{16-18}$ Two ways to enhance chances of long-term success in uveitis patients going for surgery without a 3-month inactivity are the use of adjunctive antimetabolites intraoperatively, ${ }^{4-6}$ and proper PUC. In our study, we found significantly less postoperative AC inflammation between eyes which were controlled perioperatively and eyes which were not with $\mathrm{P}$ values $<0.001$ at 1 and 3 months and 0.001 at 6 months. In addition, IOP was significantly lower in eyes with PUC (P value of 0.004, 0.001 at 3 and 6 months and $<0.001$ afterwards). In addition, patients with PUC had significantly lower average of antiglaucoma drops and higher risk of another glaucoma surgery ( $\mathrm{P}<0.001$ for both).

The two likely mechanisms involved in late surgical failure include the presence of proinflammatory cytokines and fibrosis at the surgical site. ${ }^{19-22}$ Previous studies have shown high levels of proinflammatory

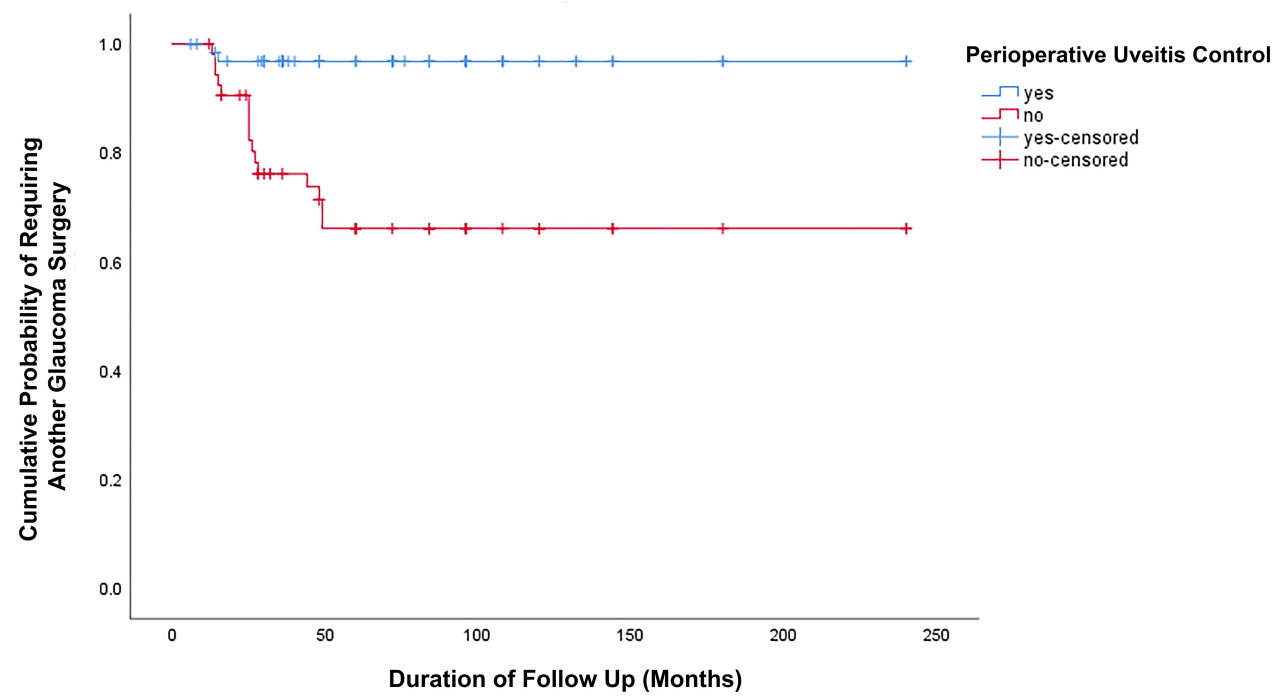

Figure 3 Cumulative probability of reoperation for IOP control was greater in the trabeculectomy group compared with the GDD group (P < 0.00 I, Log rank test). Two eyes had reoperation in eyes with PUC; however, 16 eyes underwent reoperation without PUC. 
Table 3 Analysis of Possible Risk Factors Which Can Result in Second Glaucoma Surgery in Eyes with UG

\begin{tabular}{|c|c|c|c|}
\hline Risk Factor & $\begin{array}{l}\text { Eyes with Repeated Surgery } \\
\qquad(n=18)\end{array}$ & $\begin{array}{l}\text { Eyes without Repeated Surgery } \\
\qquad(n=102)\end{array}$ & Significance \\
\hline Age (years) & $40 \pm 20.6$ & $36.9 \pm 17.3$ & 0.491 \\
\hline Gender (M:F) & $8: 10$ & 43:59 & 0.856 \\
\hline Duration of glaucoma & $80.5 \pm 64.9$ & $51.7 \pm 40.3$ & 0.013 \\
\hline Duration of uveitis & $115.0 \pm 81.6$ & $75.5 \pm 52.6$ & 0.008 \\
\hline Anatomical location & & & 0.245 \\
\hline Anterior uveitis & 12 & 47 & \\
\hline Intermediate uveitis & I & 15 & \\
\hline Panuveitis & 5 & 40 & \\
\hline Uveitis diagnosis & $\begin{array}{c}\text { Idiopathic anterior nongranulomatous } \\
\text { uveitis (7) } \\
\text { Behcet disease (3) } \\
\text { Others (8) }\end{array}$ & $\begin{array}{c}\text { VKH (27) } \\
\text { Idiopathic anterior nongranulomatous } \\
\text { uveitis (24) } \\
\text { Presumed intraocular TB (13) } \\
\text { Others (38) }\end{array}$ & 0.258 \\
\hline $\begin{array}{l}\text { Use of preoperative systemic medications } \\
\text { Yes } \\
\text { No }\end{array}$ & $\begin{array}{c}6 \\
12\end{array}$ & $\begin{array}{l}60 \\
42\end{array}$ & 0.045 \\
\hline $\begin{array}{l}\text { Number of preoperative systemic uveitis } \\
\text { medications }\end{array}$ & $0.61 \pm 0.9$ & $1.08 \pm 1.07$ & 0.088 \\
\hline $\begin{array}{l}\text { Uveitis activity preop } \\
\text { Active } \\
\text { Inactive }\end{array}$ & $\begin{array}{c}6 \\
12\end{array}$ & $\begin{array}{l}30 \\
72\end{array}$ & 0.738 \\
\hline Preoperative IOP & $33.4 \pm 6.9$ & $33.49 \pm 7.9$ & 0.982 \\
\hline Type of surgery & & & 0.467 \\
\hline GDD & 7 & 41 & \\
\hline Trabeculectomy with MMC & 7 & 29 & \\
\hline DS with MMC & 2 & 26 & \\
\hline CPC & 2 & 6 & \\
\hline
\end{tabular}

Abbreviations: CPC, cyclophotocoagulation; DS, deep sclerectomy; F, females; GDD, glaucoma drainage device; IOP, intraocular pressure; M, males; MMC, mitomycin C; VKH, Vogt Koyanagi Harada.

cytokines is association with the various types of uveitis. $^{23-25}$ Interleukin-6 (IL-6), Monocyte Chemoattractant Protein-1 (MCP-1), and vascular endothelial growth factor (VEGF) were all higher in eyes with UG than in eyes of patients with primary open angle glaucoma. ${ }^{26}$ In addition, higher levels of tumor necrosis factor-alpha (TNF- $\alpha$ ), interleukin-8 (IL8 ) and platelet-derived growth factors (PDGF) were found in patients with inflammatory cells in the AC. ${ }^{26}$ These proinflammatory cytokines are thought to lead to a slow remodeling of extracellular matrix over time leading to a higher risk of surgical failure. ${ }^{19}$
In previous studies ${ }^{9,27-29}$ which evaluated the success of GDD in UG, different courses of uveitis management were used (Table 4). Factors like preoperative initiation of anti-inflammatory agents, route of medications administered, dosage regimen and duration of perioperative treatment were variable. This variability in perioperative management approaches was caused by different anatomical locations of inflammation, various uveitic entities, duration of uveitis control and level of inflammation preoperatively among UG patients.

Da Mata et $\mathrm{al}^{9}$ studied the safety and efficacy of Ahmed glaucoma valve (AGV) in 21 eyes with UG. The 
Table 4 Summary of Previous Perioperative Uveitis Control (PUC) Regimens in Patients Who Had Glaucoma Surgeries

\begin{tabular}{|c|c|c|c|}
\hline Study & Preoperative Regimen & Postoperative Regimen & Results \\
\hline Da Mata et $\mathrm{al}^{9}$ & $\begin{array}{l}\text { Oral prednisolone } 1 \mathrm{mg} / \mathrm{kg} / \text { day until the } \\
\text { inflammation is inactive }\end{array}$ & Tapering of prednisolone over 4 weeks & $\begin{array}{l}\text { IOP } 11.6 \pm 3.8 \text { at } 2 \\
\text { years }\end{array}$ \\
\hline Papadaki et $\mathrm{al}^{27}$ & $\begin{array}{l}\text { Oral prednisolone } 1 \mathrm{mg} / \mathrm{kg} / \text { day for } 3 \text { days } \\
\text { Topical prednisolone } 1 \% \text { eight times daily } \\
\text { for } 2 \text { days }\end{array}$ & Tapering of prednisolone over 4 weeks & $\begin{array}{l}39 \% \text { success rates } \\
\text { at } 4 \text { years }^{\mathrm{a}}\end{array}$ \\
\hline Bao et $\mathrm{al}^{28}$ & None & Oral prednisolone $1 \mathrm{mg} / \mathrm{kg} /$ day tapered over 3 weeks & $\begin{array}{l}\text { IOP } 13.1 \pm 3.7 \text { at } 5 \\
\text { years }\end{array}$ \\
\hline Sungur et $\mathrm{al}^{29}$ & None & $\begin{array}{l}\text { Oral fluocortolone I } \mathrm{mg} / \mathrm{kg} \text { for } 3 \text { days followed by } \\
\text { a tapering. } \\
\text { Topical prednisolone } 1 \% \text { eye drops hourly. } \\
\text { Topical ketorolac tromethamine } 0.5 \% \text {, or nepafenac } \\
0.1 \% \text { eye drops four times daily }\end{array}$ & $\begin{array}{l}63 \% \text { success at } 4 \\
\text { years }^{b}\end{array}$ \\
\hline
\end{tabular}

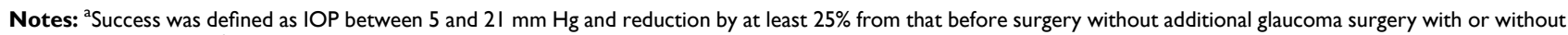
glaucoma medications. 'buccess was defined as having IOP between 6 and $21 \mathrm{~mm} \mathrm{Hg}$ with or without anti-glaucomatous medications and no need for further glaucoma surgery or tube extraction surgery.

Abbreviations: IOP, intraocular pressure; kg, kilogram, mg, milligram.

uveitic entities included juvenile rheumatoid arthritis (7), herpes simplex virus (4), idiopathic anterior uveitis (3), human leukocyte antigen-B27 (HLA-B27)-associated uveitis (3), sarcoidosis (2), and congenital syphilis (2). Surgeries were performed when uveitis was under control, although absolute quiescence was not mandatory. Preoperatively, a $1 \mathrm{mg} / \mathrm{kg}$ /day oral prednisolone was used until uveitis was inactive. Postoperatively, oral steroids were tapered over 4 weeks. After 2 years, no eyes had decrease in vision and the average IOP was $11.6 \pm 3.8$ $\mathrm{mmHg}$. Although the majority of eyes had anterior uveitis (80.9\%), the high rate of additional surgeries (52\%) required might explain the aggressive uveitis management used in their study which has led to good visual and clinical outcomes.

Papadaki et $\mathrm{al}^{27}$ studied the long-term effect of AGV in 60 eyes with UG over a 4 year period. $60 \%$ of the eyes included had anterior uveitis, 35\% panuveitis, 3\% had intermediate uveitis and $1 \%$ had posterior uveitis. The PUC regimen was used as required. A $1 \mathrm{mg} / \mathrm{kg} /$ day oral prednisolone 3 days before surgery and tapered over 1 month postoperatively. Topical prednisolone acetate $1 \% 8$ times daily 2 days was used before surgery. $43 \%$ of eyes required a combined glaucoma surgery with pars plana vitrectomy, phacoemulsification, penetrating keratoplasty, intraocular lens explantation or anterior vitrectomy. The control of IOP without serious complications was $57 \%$ and $39 \%$ at 1 and 4 years, respectively. The authors concluded that AGV was moderately successful in UG and long-term success rates were enhanced with the use of glaucoma medications. Success rates might have been increased through tighter and longer duration of uveitis control, especially with the considerably high rate of panuveitis and combined surgeries among operated eyes.

Bao et $\mathrm{al}^{28}$ reported 5-year results of AGV in 69 eyes with UG. $77.6 \%$ had anterior uveitis, $10.4 \%$ had panuveitis, $7.5 \%$ had posterior uveitis and $4.5 \%$ had intermediate uveitis. In this study, the authors ensured a 6-month inactivity in all included eyes. In addition, patients were given $1 \mathrm{mg} / \mathrm{kg}$ /day oral prednisolone for 3 weeks. Additional cataract surgery was performed in 9 eyes and 2 eyes had additional vitrectomy. The average IOP dropped from 30.8 $\mathrm{mmHg}$ to $12.9,13.8$ and $13.1 \mathrm{mmHg}$ after 1,2 and 5 years, respectively. The 6-month duration of uveitis inactivity aimed before surgical intervention might have played a role in achieving these good outcomes. Unfortunately, it is difficult to ensure uveitis inactivity for 6 months in UG patients prior to undergoing glaucoma surgery. Postoperative oral steroids might not have been needed in all patients as well.

Sungur et $\mathrm{al}^{29}$ reported the 4-year outcome of AGV in 46 eyes with UG. Most common diagnoses were idiopathic anterior uveitis (17.4\%), ankylosing spondylitis (17.4\%) Fuchs heterochromic iridocyclitis (17.4\%) pars planitis (15.2\%) and viral anterior uveitis (10.9\%). 69.5\% were quiet for 3 months before surgery, $17.4 \%$ had uveitis activity within 3 months and $13 \%$ of eyes were considered active (had 2+ AC cells or more) at the time of surgery. 
Postoperatively, patients were given oral fluocortolone $1 \mathrm{mg} / \mathrm{kg}$ for 3 days followed by a tapering, topical prednisolone $1 \%$ eye drops hourly and topical nonsteroidal anti-inflammatory drops (NSAIDs) drops four times daily. Average IOP dropped from $30 \mathrm{mmHg}$ to 13.8 and 11.9 $\mathrm{mmHg}$ at 1 and 5 years respectively. Eyes with inflammation at the time of $\mathrm{AGV}$ implantation significantly needed anti-glaucomatous medications $(\mathrm{P}=0.011)$. The insignificant difference between eyes which had a relapse within 3 months from quiet eyes further weakens the 3-month rule in UG surgery. In our study, there was no significant difference in the postoperative antiglaucoma drops number between eyes with active and inactive inflammations $(\mathrm{P}=$ 0.357). The possible explanation is the inclusion of trace and $1+$ cells in the $\mathrm{AC}$ among active uveitis eyes.

In our uveitis control regimen, the variability of the anatomical locations in uveitis was taken into consideration (Figure 1). For anterior uveitis, the use of topical steroids which have high penetration to the $\mathrm{AC}$ can be enough to control anterior uveitis and reasonable concentrations in the $\mathrm{AC}$ can be achieved by frequent applications. ${ }^{30}$ In intermediate uveitis, systemic steroids need to be used in active inflammation. The choice between oral and intravenous steroids can be made according to the level of uveitis activity. In quiet eyes, the frequent topical steroids are usually sufficient to control inflammation localized induced at the surgical site. While in eyes with active inflammation, oral and intravenous steroids are needed perioperatively. The third category of uveitis which is associated with UG is panuveitis. In these patients, serious ophthalmic complications can occur from improper uveitis control, including optic atrophy, vascular occlusions, macular atrophy, retinal detachment and phthisis bulbi. ${ }^{31}$ On the other hand, multiple ocular and systemic side effects of systemic steroids need to be considered. Osteoporosis, cardiovascular disease, impaired wound healing, alterations in glucose and lipid metabolism, and psychiatric disturbances are associated with long-term systemic steroids use. ${ }^{32}$ Used for short durations to treat acute illnesses, systemic steroids can cause avascular necrosis, serious varicella-zoster attacks and severe mood changes. ${ }^{33}$

In a subgroup analysis between eyes with repeated surgery and eyes which did not have repeated surgery, only 2 eyes (11.1\%) had PUC. Statistically significant differences in the duration of glaucoma $(\mathrm{P}=0.013)$, duration of uveitis ( $\mathrm{P}=0.008)$, the use of preoperative systemic uveitis medications $(0.045)$ and PUC $(\mathrm{P}<0.001)$ were found. The long duration and chronicity of uveitis leads to an irreversible breach in the blood-aqueous barrier accompanied by elevated aqueous protein levels. ${ }^{34}$ Accumulation of proteins in aqueous leads to progressive blockage of or damage to the trabecular meshwork. ${ }^{21}$ A similar effect can be implied after glaucoma surgeries. Another explanation is the persistent remodeling induced by inflammation which further increases the risk of failure. The use of systemic immunomodulatory agents is critical for a proper control of uveitis, especially in patients who need a long duration of uveitis management. It is well known that patients treated aggressively with antiinflammatory therapy have a better clinical course of the UG. ${ }^{35}$ Although the type of glaucoma surgery was dependent on the evaluation of the glaucoma surgeon, a higher number of CPC was noted among patient who did not have PUC compared to patients who did have PUC (6 versus 2 patients, respectively). This might represent a possible confounder as a high rate of retreatment is usually needed in UG patients who had CPC. ${ }^{36}$ Other observed differences between the two groups of patients include older age, longer durations of glaucoma and uveitis in patients who did not have PUC, which in turn might have contributed to the higher rates of second procedures in these patients.

Limitations of the present analysis include the retrospective nature of the study which was performed at a single tertiary ophthalmology center and the relatively short postoperative follow-up period. The PUC protocol used in uveitic glaucoma patients was not found in the previous literature. Further studies are needed to evaluate the efficacy of other protocols, as well as prospective studies which compare between different PUC protocols for uveitic glaucoma patients. We excluded 6 eyes which developed surgery-related complications. However, the inability to evaluate these eyes postoperatively might represent a potential confounder in this study.

In conclusion, our study demonstrated significantly lower grades of AC inflammation and lower levels of IOP after glaucoma surgeries over 2 years in patients who had perioperative UG control. Proper PUC leads to a significantly lower number of repeated glaucoma surgeries and an average number of antiglaucoma drops Long durations of glaucoma and uveitis are associated with a higher risk of repeated glaucoma surgeries. Proper uveitis control using systemic immunomodulatory therapy can help in reducing the risk of failure of glaucoma surgeries. 


\section{Abbreviations}

5FU, 5-fluorouracil; AC, anterior chamber; AGV, Ahmed glaucoma valve; ANOVA, analysis of variance; DS, deep sclerectomy; GDD, glaucoma drainage devices; HLA-B27, human leukocyte antigen- B27; IL-6, Interleukin-6; IL-8, interleukin-8; IOP, intraocular pressure; $\mathrm{kg}$, kilogram; KKESH, King Khaled Eye Specialist Hospital; logMAR, logarithm of minimal angle of resolution; MCP-1, Monocyte Chemoattractant Protein-1; mg, milligram; MMC, mitomycin C; NSAID, nonsteroidal anti-inflammatory drops; PDGF, platelet-derived growth factors; PUC, perioperative uveitis control; SPSS, Statistical Package for Social Sciences; SUN, Standardization of Uveitis Nomenclature; TNF- $\alpha$, tumor necrosis factor-alpha; UG, uveitic glaucoma; VA, visual acuity; VEGF, vascular endothelial growth factor; VKH, Vogt Koyanagi Harada disease.

\section{Data Sharing Statement}

The original data used to support the findings of this study are available from the corresponding authors upon request.

\section{Ethical Statement}

Patient consent to review their medical records was not required by the Institutional Review Board of KKESH because no identifiable data were obtained and all patient data are kept confidential.

\section{Funding}

There is no funding to report.

\section{Disclosure}

The authors declare that they have no conflicts of interest for this work.

\section{References}

1. Neri P, Azuara-Blanco A, Forrester JV. Incidence of glaucoma in patients with uveitis. J Glaucoma. 2004;13(6):461-465. doi:10.1097/ 01.ijg.0000146391.77618.d0

2. Kalogeropoulos D, Sung VC. Pathogenesis of uveitic glaucoma. $J$ Curr Glaucoma Pract. 2018;12(3):125-138. doi:10.5005/jpjournals-10028-1257

3. Kalin-Hajdu E, Hammamji K, Gagné S, Harasymowycz P. Outcome of viscodilation and tensioning of Schlemm's canal for uveitic glaucoma. Can J Ophthalmol. 2014;49(5):414-419. doi:10.1016/j. jcjo.2014.07.001

4. Jampel HD, Jabs DA, Quigley HA. Trabeculectomy with 5-fluorouracil for adult inflammatory glaucoma. Am J Ophthalmol. 1990;109(2):168-173. doi:10.1016/s0002-9394(14)75982-3

5. Towler HM, Bates AK, Broadway DC, Lightman S. Primary trabeculectomy with 5-fluorouracil for glaucoma secondary to uveitis. Ocul Immunol Inflamm. 1995;3(3):163-170. doi:10.3109/ 09273949509069109
6. Patitsas CJ, Rockwood EJ, Meisler DM, Lowder CY. Glaucoma filtering surgery with postoperative 5-fluorouracil in patients with intraocular inflammatory disease. Ophthalmology. 1992;99 (4):594-599. doi:10.1016/s0161-6420(92)31950-5

7. Hill RA, Nguyen QH, Baerveldt G, et al. Trabeculectomy and molteno implantation for glaucomas associated with uvettis. Ophthalmology. 1993;100(6):903-908. doi:10.1016/s0161-6420(93)31556-3

8. Gil-Carrasco F, Salinas-van Orman E, Recillas-Gispert C, et al. Ahmed valve implant for uncontrolled uveitic glaucoma. Ocul Immunol Inflamm. 1998;6:27-37. doi:10.1076/ocii.6.1.27.8078

9. Da Mata A, Burk SE, Netland PA, Baltatzis S, Christen W, Foster CS. Management of uveitic glaucoma with ahmed glaucoma valve implantation. Ophthalmology. 1999;106(11):2168-2172. doi:10.1016/S0161-6420(99)90500-6

10. Moorthy RS, Mermoud A, Baerveldt G, Minckler DS, Lee PP, Rao NA. Glaucoma associated with uveitis. Surv Ophthalmol. 1997;41(5):361-394. doi:10.1016/s0039-6257(97)00006-4

11. Jabs DA, Nussenblatt RB, Rosenbaum JT; Standardization of Uveitis Nomenclature (SUN) Working Group. Standardization of uveitis nomenclature for reporting clinical data. Results of the first international workshop. Am J Ophthalmol. 2005;140(3):509-516. doi:10.1016/j.ajo.2005.03.057

12. AlDarrab A, Malik R. Bilateral deep sclerectomy with microperforations as a successful secondary procedure in aniridia-associated glaucoma. Middle East Afr J Ophthalmol. 2018;25(1):52-55. doi:10.4103/meajo.MEAJO_291_17

13. Albahlal A, Alshamrani A, Khandekar R, Malik R. Outcome of surgical management of glaucoma following complex retinal detachment repair with silicone oil tamponade: drainage implant versus cyclophotocoagulation. $J$ Glaucoma. 2020;29(3):198-204. doi:10.1097/IJG.0000000000001435

14. Forster DJ, Rao NA, Hill RA, Nguyen QH, Baerveldt G. Incidence and management of glaucoma in vogt-koyanagi-harada syndrome. Ophthalmology. 1993;100(5):613-618. doi:10.1016/s0161-6420(93) 31604-0

15. Moorthy RS, Inomata H, Rao NA. Vogt-koyanagi-harada syndrome. Surv Ophthalmol. 1995;39(4):265-292. doi:10.1016/s0039-6257(05) 80105-5

16. Giuliari GP, Chang PY, Thakuria P, Hinkle DM, Foster CS. Pars plana vitrectomy in the management of paediatric uveitis: the Massachusetts Eye Research and Surgery Institution experience. Eye. 2010;24(1):7-13. doi:10.1038/eye.2009.294

17. Quinones K, Choi JY, Yilmaz T, Kafkala C, Letko E, Foster CS. Pars plana vitrectomy versus immunomodulatory therapy for intermediate uveitis: a prospective, randomized pilot study. Ocul Immunol Inflamm. 2010;18(5):411-417. doi:10.3109/09273948.2010.501132

18. Ahn JK, Chung H, Yu HG. Vitrectomy for persistent panuveitis in behcet's disease. Ocul Immunol Inflamm. 2005;13(6):447-453. doi:10.1080/09273940591004232

19. Zhang Z, Miao Y, Wang J, Zhou M, Fu M, Wang Y. Matricellular protein levels in aqueous humor and surgical outcomes of trabeculectomy. Invest Ophthalmol Vis Sci. 2018;59(10):3906-3910. doi:10.1167/iovs.18-24534

20. Ladas JG, Yu F, Loo R, et al. Relationship between aqueous humor protein level and outflow facility in patients with uveitis. Invest Ophthalmol Vis Sci. 2001;42(11):2584-2588.

21. Epstein DL, Hashimoto JM, Grant WM. Serum obstruction of aqueous outflow in enucleated eyes. Am $J$ Ophthalmol. 1978;86 (1):101-105. doi:10.1016/0002-9394(78)90023-5

22. Peretz WL, Tomasi T. Aqueous humor proteins in uveitis. Immunoelectrophoretic and gel diffusion studies on normal and pathological human aqueous humor. Arch Ophthalmol. 1961;65:20-23. doi:10.1001/archopht.1961.01840020022005

23. Norose K, Yano A, Wang XC, et al. Dominance of activated T cells and interleukin-6 in aqueous humor in vogt-koyanagi-harada disease. Invest Ophthalmol Vis Sci. 1994;35(1):33-39. 
24. Abu El-Asrar AM, Struyf S, Descamps FJ, et al. Chemokines and gelatinases in the aqueous humor of patients with active uveitis. $\mathrm{Am}$ J Ophthalmol. 2004;138(3):401-411. doi:10.1016/j.ajo.2004.04.046

25. Abu El-Asrar AM, Struyf S, Kangave D, et al. Cytokine and CXC chemokine expression patterns in aqueous humor of patients with presumed tuberculous uveitis. Cytokine. 2012;59(2):377-381. doi:10.1016/j.cyto.2012.04.030

26. Ohira S, Inoue T, Iwao K, Takahashi E, Tanihara H, Acott TS. Factors influencing aqueous proinflammatory cytokines and growth factors in uveitic glaucoma. PLoS One. 2016;11(1):e0147080. doi:10.1371/journal.pone.0147080

27. Papadaki TG, Zacharopoulos IP, Pasquale LR, Christen WB, Netland PA, Foster CS. Long-term results of Ahmed glaucoma valve implantation for uveitic glaucoma. Am J Ophthalmol. 2007;144(1):62-69. doi:10.1016/j.ajo.2007.03.013

28. Bao N, Jiang ZX, Coh P, Tao LM. Long-term outcomes of uveitic glaucoma treated with ahmed valve implant in a series of Chinese patients. Int $J$ Ophthalmol. 2018;11(4):629-634. doi:10.18240/ ijo.2018.04.15

29. Sungur G, Yakin M, Eksioglu U, Satana B, Ornek F. Assessment of conditions affecting surgical success of ahmed glaucoma valve implants in glaucoma secondary to different uveitis etiologies in adults. Eye. 2017;31(10):1435-1442. doi:10.1038/eye.2017.84
30. McGhee CN. Pharmacokinetics of ophthalmic corticosteroids. $\mathrm{Br}$ J Ophthalmol. 1992;76(11):681-684. doi:10.1136/bjo.76.11.681

31. Tugal-Tutkun I, Onal S, Altan-Yaycioglu R, Huseyin Altunbas H, Urgancioglu M. Uveitis in behçet disease: an analysis of 880 patients. Am J Ophthalmol. 2004;138(3):373-380. doi:10.1016/j.ajo.2004.03.022

32. Rice JB, White AG, Scarpati LM, Wan G, Nelson WW. Long-term systemic corticosteroid exposure: a systematic literature review. Clin Ther. 2017;39(11):2216-2229. doi:10.1016/j.clinthera.2017.09.011

33. Richards RN. Side effects of short-term oral corticosteroids. J Cutan Med Surg. 2008;12(2):77-81. doi:10.2310/7750.2008.07029

34. Ladas JG, Wheeler NC, Morhun PJ, Rimmer SO, Holland GN. Laser flare-cell photometry: methodology and clinical applications. Surv Ophthalmol. 2005;50(1):27-47. doi:10.1016/j.survophthal.2004.10.004

35. Siddique SS, Suelves AM, Baheti U, Foster CS. Glaucoma and uveitis. Surv Ophthalmol. 2013;58(1):1-10. doi:10.1016/j. survophthal.2012.04.006

36. Schlote T, Derse M, Zierhut M. Transscleral diode laser cyclophotocoagulation for the treatment of refractory glaucoma secondary to inflammatory eye diseases. Br J Ophthalmol. 2000;84(9):999-1003. doi:10.1136/bjo.84.9.999
Clinical Ophthalmology

\section{Publish your work in this journal}

Clinical Ophthalmology is an international, peer-reviewed journal covering all subspecialties within ophthalmology. Key topics include: Optometry; Visual science; Pharmacology and drug therapy in eye diseases; Basic Sciences; Primary and Secondary eye care; Patient Safety and Quality of Care Improvements. This journal is indexed on PubMed

\section{Dovepress}

Central and CAS, and is the official journal of The Society of Clinical Ophthalmology (SCO). The manuscript management system is completely online and includes a very quick and fair peer-review system, which is all easy to use. Visit http://www.dovepress.com/ testimonials.php to read real quotes from published authors. 